\title{
Soybean Cultivar Responses to Sclerotinia sclerotiorum in Field and Controlled Environment Studies
}

\author{
S. N. Wegulo, X. B. Yang, and C. A. Martinson, Department of Plant Pathology, Iowa State University, Ames \\ 50011
}

\author{
ABSTRACT \\ Wegulo, S. N., Yang, X. B., and Martinson, C. A. 1998. Soybean cultivar responses to Sclero- \\ tinia sclerotiorum in field and controlled environment studies. Plant Dis. 82:1264-1270.
}

The responses of 12 soybean cultivars to Sclerotinia sclerotiorum were evaluated under field and controlled environment conditions. The 12 cultivars were planted in fields naturally or artificially infested with $S$. sclerotiorum and evaluated for disease incidence. In controlled environment studies, the cultivars were compared with respect to lesion size on detached leaves and stems inoculated with mycelial disks, incidence of stem rot following mycelial inoculation of foliage, lesion lengths on stems discolored by oxalic acid, and levels of soluble pigment(s) in stems. Significant differences $(P \leq 0.05)$ in disease incidence, lesion sizes, and levels of soluble pigment(s) were detected among the 12 cultivars in all evaluations, but ranking of cultivars varied among methods and experiments within methods. Corsoy 79 and S19-90 were consistently most resistant in all methods; whereas Kenwood, A2242, Bell, and Williams 82 were least resistant. Pearson correlation coefficients $(R)$ for disease incidence between location years in field experiments (FE) ranged from 0.86 to 0.95 . $R$ values between FE and controlled environment experiments (CEE) ranged from 0.01 to 0.62 for detached leaf assays (DLA), -0.20 to 0.47 for lesion lengths on stems inoculated with mycelial disks (LLM), 0.38 to 0.45 for incidence of stem rot from mycelial inoculation of foliage (MIF), 0.08 to 0.66 for lesion lengths on stems discolored by oxalic acid (LLO), and -0.55 to -0.37 for levels of soluble stem pigment(s) (SSP). Absolute values of $R$ between FE and CEE were 0.40 or greater in 40, 17, 33, 29 , and $83 \%$ of all correlation analyses for DLA, LLM, MIF, LLO, and SSP, respectively. Spearman's coefficients of rank correlation $\left(r_{s}\right)$ between FE and CEE based on average performance were $0.55,-0.20,0.40,0.42$, and -0.44 for DLA, LLM, MIF, LLO, and SSP, respectively. Disease development was slow when foliage was inoculated with a mycelial suspension. Based on experiment (E) by cultivar (C) interaction and $r_{s}$ values between replicate experiments within each method, determination of soluble stem pigment levels $\left(0.86 \leq r_{s} \leq 0.97\right.$; $P<0.001$ for $100 \%$ of six analyses; $P=0.98$ for $\mathrm{E} \times \mathrm{C}$ interaction) and measurement of lesion lengths on stems discolored by oxalic acid $\left(0.27 \leq r_{s} \leq 0.85 ; r_{s} \geq 0.58\right.$ and $P \leq 0.05$ for $68 \%$ of 28 analyses; $P=0.07$ for $\mathrm{E} \times \mathrm{C}$ interaction) were the most repeatable methods. The results from this study suggest that determination of levels of soluble pigments in stems, measurement of lesion lengths on stems discolored by oxalic acid, and the detached leaf assay may be better than mycelial inoculation of stems or foliage in evaluating soybean cultivars for field resistance to $S$. sclerotiorum.

Additional keywords: ascospore inoculation, colonized carrot inoculation, excised stem technique, limited term inoculation

Stem rot of soybean caused by Sclerotinia sclerotiorum (Lib.) de Bary has recently increased in prevalence, incidence, and severity in the soybean growing areas of the midwestern United States and Canada $(3,7,16)$. Increased prevalence, incidence, and severity of the disease have

Corresponding author: X. B. Yang

E-mail address: xbyang@iastate.edu

Journal Paper J-17872 of the Iowa Agriculture and Home Economics Experiment Station, Project No. 2869. Portion of a Ph.D. dissertation by S. N. Wegulo submitted to the Graduate College, Iowa State University. This research was funded in part by the Iowa Soybean Promotion Board.

Accepted for publication 14 August 1998.

Publication no. D-1998-0916-01R

(C) 1998 The American Phytopathological Society the growth chamber (3), and in the laboratory $(6,29,30)$. The limited term inoculation (LTI) methods of Hunter et al. (24) and Cline and Jacobsen (7), or modifications of these methods, have been used by some investigators $(3,32)$ to evaluate soybean cultivars for resistance to $S$. sclerotiorum. Other investigators $(29,30)$ have used the excised stem technique of Chun et al. (6). The detached leaf assay has not been reported for inoculations of soybean leaves with $S$. sclerotiorum, but it has been used by Pratt and Rowe (33) to inoculate alfalfa leaves with $S$. trifoliorum.

Because oxalic acid is very important in pathogenesis by $S$. sclerotiorum $(13,14)$, some investigators have utilized the acid in developing screening techniques for identification of cultivars resistant to the pathogen. Noyes and Hancock (31) developed a screening test based on resistance of sunflower (Helianthus annuus) leaf cells to lysis in various concentrations of oxalic acid. Tu (36) distinguished between tolerant and susceptible white bean (Phaseolus vulgaris) cultivars on the basis of differences in the rate of diffusion of oxalic acid in leaf tissue. These studies have shown that oxalic acid may be a useful tool for screening cultivars and breeding germ plasm for resistance to $S$. sclerotiorum.

Results from most methods of screening soybean cultivars for resistance to $S$. sclerotiorum have been variable. Cline and Jacobsen (7) found LTI to be the only method to successfully detect differences in susceptibility among soybean cultivars inoculated using two other methods (ascospore inoculations and colonized carrot inoculations). Chun et al. (6) found soybean cultivars of maturity groups $0, \mathrm{I}$, II, and III to differ in their responses to Sclerotinia stem rot when assessed by the excised stem technique, but results of different experiments were frequently inconsistent. In the same study (6), lesion lengths on stems of soybean cultivars assessed by the excised stem technique showed varying correlations with incidence of Sclerotinia stem rot in field experiments. Using the excised stem technique, Nelson et al. (30) found no correlation between field evaluations of 15 soybean cultivars and laboratory evaluations of the same cultivars. On the basis of these results, the authors (30) suggested that a laboratory test measuring stem decay may be unreliable for identifying field resistance to $S$. sclerotiorum 
and may therefore have little value in a breeding program.

The use of ascospores as a method of inoculation when evaluating soybean cultivars for resistance to $S$. sclerotiorum in controlled environment conditions is timeconsuming because it requires preconditioning of sclerotia for carpogenic germination $(8,10)$ and the collection and storage of ascospores. The ever-increasing soybean yield losses from Sclerotinia stem rot $(11,38)$ justify the effort to identify soybean germ plasm with resistance to the disease. Likewise, there is a need to develop economical, reliable, and time-saving techniques to identify resistant soybean germ plasm. The purpose of this study was to develop greenhouse, growth chamber, or laboratory screening methods that may be useful in evaluating soybean cultivars for resistance to $S$. sclerotiorum under field conditions.

\section{MATERIALS AND METHODS}

Field trials. Twelve soybean cultivars that presumably differed in their response to Sclerotinia stem rot were planted in Iowa in the spring of 1995 and 1996 at the Hinds Research Farm near Ames $\left(42^{\circ} \mathrm{N}\right.$ latitude, $93.6^{\circ} \mathrm{W}$ longitude), the Kanawha Research Farm at Kanawha $\left(43^{\circ} \mathrm{N}\right.$ latitude, $93.8^{\circ} \mathrm{W}$ longitude), and in a commercial field near Humboldt $\left(42.7^{\circ} \mathrm{N}\right.$ latitude, $94.2^{\circ} \mathrm{W}$ longitude). Field plots at the Hinds and the Kanawha Research farms were artificially infested with sclerotia of $S$. sclerotiorum obtained from sunflower fields at a rate of 80 sclerotia per $\mathrm{m}^{2}$. Field plots near Humboldt were naturally infested with S. sclerotiorum. Cultivars were chosen to include Corsoy 79, which has been reported to be moderately resistant to S. sclerotiorum $(7,18)$, and some private and public cultivars commonly grown in Iowa. Williams 82 was included as a susceptible check. Cultivars were arranged in a randomized complete block design with three or four replications. Plot size was 5 by $2.5 \mathrm{~m}$, row spacing was $0.19,0.38$, or $0.76 \mathrm{~m}$, and planting rate was 20 or 30 seeds per meter of row. Disease incidence was measured on 3 September 1995 and 4 September 1996 near Humboldt, and on 12 September 1996 at Kanawha.

Inoculum source for controlled environment experiments. A sclerotium of an isolate of S. sclerotiorum was obtained from soybean seed harvested from a naturally infested commercial field near Humboldt, Iowa, in 1995. The isolate, designated isolate A, was surface-sterilized as described by Nelson et al. (28) and cultured on potato dextrose agar (PDA). The PDA plate containing the sclerotium was incubated at $20^{\circ} \mathrm{C}$ with 12 -h light and 12 -h dark. Mature daughter sclerotia were kept in sterile petri plates at $20^{\circ} \mathrm{C}$, or were cultured on PDA to obtain mycelium needed for inoculations or to produce more sclerotia.
Detached leaf assays. Twelve soybean cultivars were grown in the greenhouse in 10-cm-diameter clay pots filled with a pasteurized clay-loam soil, five plants per pot. Plants were fertilized with soluble 2020-20 fertilizer once every 2 to 3 weeks. Cultivars were arranged in a randomized complete block design with three replications. At the R1 to R3 growth stages (early flowering to early podding; 12), the middle leaflet or one of the lateral leaflets was detached from the third-youngest trifoliate leaf and surface-sterilized in the laboratory in a solution containing $47.5 \%$ ethanol and $2.6 \%$ sodium hypochlorite for $5 \mathrm{~s}$. A 2-mm-diameter wound was created 1 to $3 \mathrm{~mm}$ from the edge of the adaxial surface of the leaflet using a nail. The leaflet was placed on $2 \%$ water agar in a $9-\mathrm{cm}-$ diameter petri plate, and a 10-mm-diameter agar disk cut from a 5- to 7-day-old culture of isolate A of $S$. sclerotium was placed over the wound. The petri plates containing the inoculated leaflets were sealed with Parafilm and incubated at $20^{\circ} \mathrm{C}$ with $12-\mathrm{h}$ light and 12-h dark for 7 days. Cultivars (leaflets) were arranged in a randomized complete block design in the incubator with three replications. Percentage of leaf area covered by the lesion was measured daily for 7 days by dividing the weight of a piece of cellulose acetate transparency with area equal to that of the lesion by the weight of a piece of transparency with area equal to that of the whole leaflet (35).

Mycelial inoculation of stems. Twelve soybean cultivars were grown in the greenhouse as described above. Cultivars were arranged in a randomized complete block design with three replications. At the R1 to R3 growth stages, each soybean stem was punctured at midheight with a nail to create a 2-mm-diameter wound. An autoclaved carrot disk with a 24-h-old mycelial culture of isolate A of $S$. sclerotiorum was placed over the wound, covered with wet cotton wool, then wrapped with Parafilm. The inoculated plants were misted in a solenoid-controlled mist chamber for $12 \mathrm{~s}$ every 6 min for 2 to 4 days and transferred to a controlled environment chamber (Conviron PG W36) at $18^{\circ} \mathrm{C}$ with $14-\mathrm{h}$ light and 10-h dark. Lesion lengths were measured daily starting 3 to 5 days after inoculation for 7 days (experiments 1 to 4) or once on the fifth day after inoculation (experiments 5 and 6). Vernier calipers were used to measure stem diameters to determine if there was a relationship between lesion length and stem diameter.

Mycelial inoculation of foliage. Twelve soybean cultivars were grown in the greenhouse as described above. Cultivars were arranged in a randomized complete block design on a greenhouse bench with three replications. An inoculum suspension was made by blending 1-week-old mycelium from a culture of isolate A of S. sclerotiorum grown on autoclaved carrot pieces. The blended mycelium-carrot mixture was suspended in 4 liters of tap water, and the suspension was broadcast once by hand onto plant foliage to runoff at the R1 growth stage. Plants were misted for $3 \mathrm{~s}$ every $6 \mathrm{~min}$. The number of plants with stem rot in each pot was determined 4 weeks after inoculation. This experiment was not repeated because of the long time between inoculation of foliage and development of measurable lesion lengths on stems.

Response to oxalic acid. Twelve soybean cultivars were grown in the greenhouse in 13-cm-diameter pots (15 to 20 plants per pot) as described above. Cultivars were arranged in a randomized complete block design with three replications. At the R1 to R3 growth stages, plants were severed approximately $0.5 \mathrm{~cm}$ above the soil line using a pair of scissors. All leaves and petioles were removed from the excised portion of each stem except the top two fully developed trifoliate leaves. Each plant was placed immediately in a $16 \times$ $150 \mathrm{~mm}$ test tube containing $10 \mathrm{ml}$ of 40 $\mathrm{mM}$ oxalic acid. Test tubes containing soybean stems were arranged vertically in test tube racks in a randomized complete block design with three replications. There were two sets of four replicate experiments. The first set was placed on a bench in a greenhouse room where temperature ranged from 22 to $35^{\circ} \mathrm{C}$, and the second set was placed in a controlled environment chamber (Conviron PG W36) at $18^{\circ} \mathrm{C}$ with 14-h light and 10-h dark. The lengths of stems discolored by oxalic acid were measured on the fourth day.

Determination of soluble pigment levels in stems. A pink pigment(s) dissolved in oxalic acid from soybean stems was observed in preliminary experiments to be greater in some resistant compared with susceptible cultivars. Four replicate experiments were conducted to determine if levels of the soluble stem pigment(s) differed among cultivars. Twelve cultivars were grown in the greenhouse in $10-\mathrm{cm}$ diameter clay pots (15 to 20 plants per pot) as described above. At the V1 or V2 growth stage, stems were severed approximately $0.5 \mathrm{~cm}$ above soil level, completely defoliated, and placed immediately in $13 \times 100 \mathrm{~mm}$ test tubes containing $5 \mathrm{ml}$ of $40 \mathrm{mM}$ oxalic acid (1 stem per test tube). Test tubes containing soybean stems were arranged vertically in test tube racks in a randomized complete block design with three replications and were incubated at $20^{\circ} \mathrm{C}$ in a $12-\mathrm{h}$ light and $12-\mathrm{h}$ dark cycle. After $48 \mathrm{~h}, 4 \mathrm{ml}$ of the oxalic acid in each test tube was transferred to 5-ml cuvettes, and absorbance was determined in a Shimatzu UV-160 spectrophotometer at 518 $\mathrm{nm}$, the wavelength of maximum absorbance.

Data analysis. Data were analyzed by the general linear models procedure. Combined analyses of experiments within methods were based on homogeneity of 
variance determined from Bartlett's test (34). Fisher's (protected) least significant difference test (34) was used to make planned pairwise means comparisons for disease incidence, lesion sizes on leaves and stems, and absorbance at $518 \mathrm{~nm}$ by soluble stem pigment(s). Pearson correlation coefficients were used to compare cultivar responses to $S$. sclerotiorum in controlled environment studies with responses of the same cultivars to the pathogen in field studies. Cultivars were ranked according to their average performance (disease incidence, percentage of leaf area covered with lesions, lesion lengths on stems, or absorbance at 518 $\mathrm{nm}$ by soluble pigment[s] from stems). Spearman's coefficients of rank correlation (34) were used to measure the correspondence between (i) ranks of cultivars in controlled environment experiments and ranks of the same cultivars in field experiments, and (ii) ranks of cultivars between replicate experiments within each method in controlled environment studies.

\section{RESULTS}

Field trials. Highly significant differences $(P=0.0001)$ in Sclerotinia stem rot incidence were found among soybean cultivars in all three field experiments conducted near Humboldt in 1995 and 1996, and at the Kanawha Research Farm in 1996. Hot and dry weather in 1995 prevented development of statistically measurable levels of disease at the Hinds and the Kanawha Research farms. At the Hinds Research Farm in 1995, infected plants were detected mainly in Williams 82 plots. Frequent irrigation at this location did not result in increased disease levels due to the high temperatures that prevailed during most of the 1995 growing season. In the three location years in which disease incidence was measured, plots in which the cultivars Dassel, Corsoy 79 (1996), S1990 , and Parker were grown had consis-

Table 1. Incidence of Sclerotinia stem rot (Sclerotinia sclerotiorum) among 12 soybean cultivars in a commercial field near Humboldt, Iowa, in 1995 and 1996 and at the Kanawha Research Farm, Iowa, 1996

\begin{tabular}{|c|c|c|c|c|c|}
\hline \multicolumn{2}{|c|}{ Humboldt, 1995} & \multicolumn{2}{|c|}{ Humboldt, 1996} & \multicolumn{2}{|c|}{ Kanawha, 1996} \\
\hline Cultivar $^{x}$ & $\begin{array}{c}\text { Incidence }^{y} \\
(\%)\end{array}$ & Cultivar & $\begin{array}{c}\text { Incidence of } \\
\text { dead plants }(\%)\end{array}$ & Cultivar & $\begin{array}{c}\text { Incidence of } \\
\text { dead plants }(\%)\end{array}$ \\
\hline A2242 & $47.3 \mathrm{a}$ & Williams 82 & $78.8 \mathrm{a}$ & A2242 & $64.0 \mathrm{a}$ \\
\hline Williams 82 & $37.3 \mathrm{ab}$ & A2242 & $70.0 \mathrm{a}$ & Williams 82 & $51.3 \mathrm{~b}$ \\
\hline Bell & $30.4 \mathrm{~b}$ & Bell & $42.8 \mathrm{~b}$ & IA2007R & $21.8 \mathrm{c}$ \\
\hline BSR 101 & $18.5 \mathrm{c}$ & IA2007R & $40.0 \mathrm{bc}$ & Kenwood & $20.6 \mathrm{c}$ \\
\hline Corsoy 79 & $14.8 \mathrm{~cd}$ & Kenwood & $33.8 \mathrm{~b}-\mathrm{d}$ & Bell & $19.9 \mathrm{c}$ \\
\hline Latham 440 & $12.9 \mathrm{~cd}$ & Latham 440 & $31.3 \mathrm{~b}-\mathrm{d}$ & BSR 101 & $18.4 \mathrm{c}$ \\
\hline IA2007 & $10.8 \mathrm{~cd}$ & BSR 101 & $27.5 b-d$ & Latham 440 & $15.9 \mathrm{~cd}$ \\
\hline Kenwood & $9.3 \mathrm{~cd}$ & Parker & $23.8 \mathrm{c}-\mathrm{e}$ & Parker & $7.4 \mathrm{de}$ \\
\hline Parker & $7.0 \mathrm{~cd}$ & S19-90 & $17.5 \mathrm{de}$ & A2506 & $6.1 \mathrm{e}$ \\
\hline S19-90 & $7.0 \mathrm{~cd}$ & A2506 & $10.0 \mathrm{e}$ & S19-90 & $2.8 \mathrm{e}$ \\
\hline Dassel & $5.3 \mathrm{~d}$ & Dassel & $9.3 \mathrm{e}$ & Corsoy 79 & $2.8 \mathrm{e}$ \\
\hline A2506 & $5.1 \mathrm{~d}$ & Corsoy 79 & $8.0 \mathrm{e}$ & Dassel & $1.6 \mathrm{e}$ \\
\hline $\mathrm{SE}^{\mathrm{z}}$ & 4.1 & & 5.6 & & 3.4 \\
\hline
\end{tabular}

${ }^{x}$ Cultivar means followed by the same letter are not significantly different at $P=0.05$ according to Fisher's (protected) least significant difference test.

${ }^{y}$ Incidence was measured on 3 and 4 September near Humboldt in 1995 and 1996, respectively, and on 12 September at Kanawha in 1996.

${ }^{\mathrm{z}}$ Standard error of the mean. tently low levels of disease; whereas Williams 82 and A2242 plots had consistently high levels of disease (Table 1).

Near Humboldt in 1995, wilted or wilting plants were visible in most of the field by the last week of July. By the second week of August, there were detectable differences in disease incidence among cultivars, with Asgrow 2242 and Williams 82 plots having the highest disease incidence and A2506, Dassel, S19-90, and Parker plots having the lowest disease incidence. Disease incidence measured on 3 September ranged from $5 \%$ in A2506 plots to $47 \%$ in A2242 plots (Table 1).

In 1996, cool, wet weather favored development of epidemic levels of Sclerotinia stem rot in most of Iowa. Near Humboldt, incidence of dead plants on 4 September was lowest in Dassel and Corsoy 79 plots (8 and $9 \%$, respectively) and highest in Williams 82 and A2242 plots (79 and $70 \%$, respectively) (Table 1). At the Kanawha Research Farm, incidence of dead plants ranged from $2 \%$ in Dassel plots to $64 \%$ in A2242 plots (Table 1).

Detached leaf assays. Lesions on detached leaves were usually visible by the second day after inoculation with agar disks containing mycelia of $S$. sclerotiorum, but were measurable 3 to 4 days after inoculation. $F$ values for cultivars (final percentage of leaf area covered with lesions) were significant $(P \leq 0.05)$ in three out of five experiments (Table 2). Although cultivar ranks varied from experiment to experiment, percentage of leaf area covered with lesions was low in at least three out of five experiments for the cultivars Corsoy 79 and S19-90, and high for the cultivars Kenwood and Williams 82 (Table 2). Experiment by cultivar interaction was highly significant $(P=0.0001)$. The rate of lesion development was linear for most cultivars in most experiments but differed among cultivars (Fig. 1)

Mycelial inoculation of stems. Soybean plants started to show wilt symptoms

Table 2. Percentage of leaf area diseased for 12 soybean cultivars in five detached leaf experiments inoculated with mycelial disks of Sclerotinia sclerotiorum and incubated for 7 days at $20^{\circ} \mathrm{C}, 1996$ to 1997

\begin{tabular}{|c|c|c|c|c|c|c|}
\hline \multirow[b]{2}{*}{ Cultivars $^{y}$} & \multicolumn{6}{|c|}{ Diseased leaf area $(\%)$} \\
\hline & 1 & 2 & 3 & 4 & 5 & Combined \\
\hline Williams 82 & 83.5 & $93.7 \mathrm{ab}$ & $93.6 \mathrm{ab}$ & $46.9 \mathrm{c}$ & 67.9 & $77.1 \mathrm{a}$ \\
\hline Kenwood & 35.7 & $100.0 \mathrm{a}$ & $100.0 \mathrm{a}$ & $60.2 \mathrm{bc}$ & 68.6 & $72.9 \mathrm{ab}$ \\
\hline Bell & 56.6 & $90.0 \mathrm{a}-\mathrm{c}$ & $71.8 \mathrm{a}-\mathrm{d}$ & $52.3 \mathrm{bc}$ & 53.5 & $64.8 \mathrm{a}-\mathrm{d}$ \\
\hline A2242 & 39.2 & $62.6 \mathrm{ef}$ & $97.9 \mathrm{a}$ & $90.7 \mathrm{a}$ & 56.6 & $69.4 \mathrm{a}-\mathrm{c}$ \\
\hline BSR 101 & 32.7 & $75.0 \mathrm{~b}-\mathrm{e}$ & $77.7 \mathrm{a}-\mathrm{d}$ & $56.9 \mathrm{bc}$ & 55.2 & $55.0 \mathrm{de}$ \\
\hline Parker & 12.5 & $68.7 \mathrm{c}-\mathrm{f}$ & $48.8 \mathrm{~d}$ & $56.6 \mathrm{bc}$ & 62.0 & $49.7 \mathrm{e}$ \\
\hline A2506 & 43.9 & $69.1 \mathrm{c}-\mathrm{f}$ & $66.4 \mathrm{~b}-\mathrm{d}$ & $55.9 \mathrm{bc}$ & 53.5 & $57.7 \mathrm{c}-\mathrm{e}$ \\
\hline IA2007 & 98.2 & 82.3 a-e & $63.8 \mathrm{~b}-\mathrm{d}$ & $64.8 \mathrm{~b}$ & 52.7 & $72.3 \mathrm{ab}$ \\
\hline Latham 440 & 42.0 & $96.8 \mathrm{ab}$ & $83.6 \mathrm{ab}$ & $93.7 \mathrm{a}$ & 44.4 & $72.1 \mathrm{ab}$ \\
\hline Dassel & 57.1 & $65.7 \mathrm{~d}-\mathrm{f}$ & $83.0 \mathrm{a}-\mathrm{c}$ & $57.8 \mathrm{bc}$ & 54.5 & $63.6 \mathrm{~b}-\mathrm{d}$ \\
\hline S1990 & 8.9 & 87.4 a-d & 75.6 a-d & $48.2 \mathrm{c}$ & 59.9 & $56.0 \mathrm{de}$ \\
\hline Corsoy 79 & 15.0 & $46.2 \mathrm{f}$ & $52.6 \mathrm{~cd}$ & $91.0 \mathrm{a}$ & 45.2 & $50.1 \mathrm{e}$ \\
\hline $\mathrm{SE}^{\mathrm{z}}$ & 5.3 & 2.4 & 3.0 & 1.3 & 1.9 & 1.3 \\
\hline
\end{tabular}

y Cultivar means followed by the same letter are not significantly different at $P=0.05$ according to Fisher's (protected) least significant difference test.

${ }^{\mathrm{z}}$ Standard error of the mean. 
within 2 to 3 days after inoculation of stems with mycelia of $S$. sclerotiorum. There was considerable variation among cultivars in the time that elapsed between inoculation and the onset of wilt symptoms. Leaves below the point of inoculation did not usually wilt, but all leaves above the point of inoculation wilted within 2 to 4 days after the onset of wilt symptoms.

There were significant differences $(P \leq$ 0.05 ) in final lesion length among cultivars in all six experiments (Table 3). Due to considerable fluctuation of cultivar ranks among experiments, experiment by cultivar interaction was highly significant $(P=$ 0.0001). In most experiments, lesions were shortest in the cultivars Corsoy 79 and S19-90 and longest in Kenwood and Williams 82 (Table 3). The rate of lesion development on stems was linear for each cultivar but differed among cultivars (Fig. 2 ). Pearson correlation between stem diameters and lesion lengths on stems was variable among cultivars, with correlation coefficients ranging from -0.54 to 0.90 for experiment 2.

Mycelial inoculation of foliage. Lesions were visible on foliage 3 to 5 days after inoculation with a carrot-water suspension containing mycelia of S. sclerotiorum. Some stems developed lesions approximately 1 week after inoculation, but disease incidence based on stem rot was not measurable until approximately 3 weeks after inoculation. There were significant differences among cultivars in incidence of stem rot 4 weeks after inoculation $(P=0.01)$. Kenwood had the highest incidence of stem rot $(93 \%)$, followed by Williams 82 (80\%); whereas Corsoy 79 and S19-90 had the lowest incidence of stem rot (20 and $27 \%$, respectively).

Response to oxalic acid. Within 10 to 15 min of placing severed stems into oxalic acid in test tubes, a bright pink color appeared where the stems were severed and was most noticeable in IA2007, Dassel,
Corsoy 79, S19-90, Bell, and A2506. The color was visible in stems of all cultivars except A2242, Parker, and Williams 82, and usually disappeared by the following day when the lower portions of stems became discolored. Significant differences $(P$ $\leq 0.05$ ) among cultivars in lesion lengths of discolored stems were found in all four experiments conducted in the greenhouse room $\left(22\right.$ to $\left.35^{\circ} \mathrm{C}\right)$ and in three out of four experiments conducted in the growth chamber at $18^{\circ} \mathrm{C}$. Although ranks of individual cultivars fluctuated among experiments, experiment by cultivar interaction was nonsignificant at the $5 \%$ probability level $(P=0.07)$. Kenwood ranked eleventh or twelfth (longest lesions) in seven of the eight experiments, Williams 82 ranked eleventh or twelfth in six of the eight experiments, and IA2007 ranked first (shortest lesions) in five of the eight experiments (Table 4). Overall, IA2007, Dassel, S1990, Latham 440, and Corsoy 79 were the five cultivars with the shortest
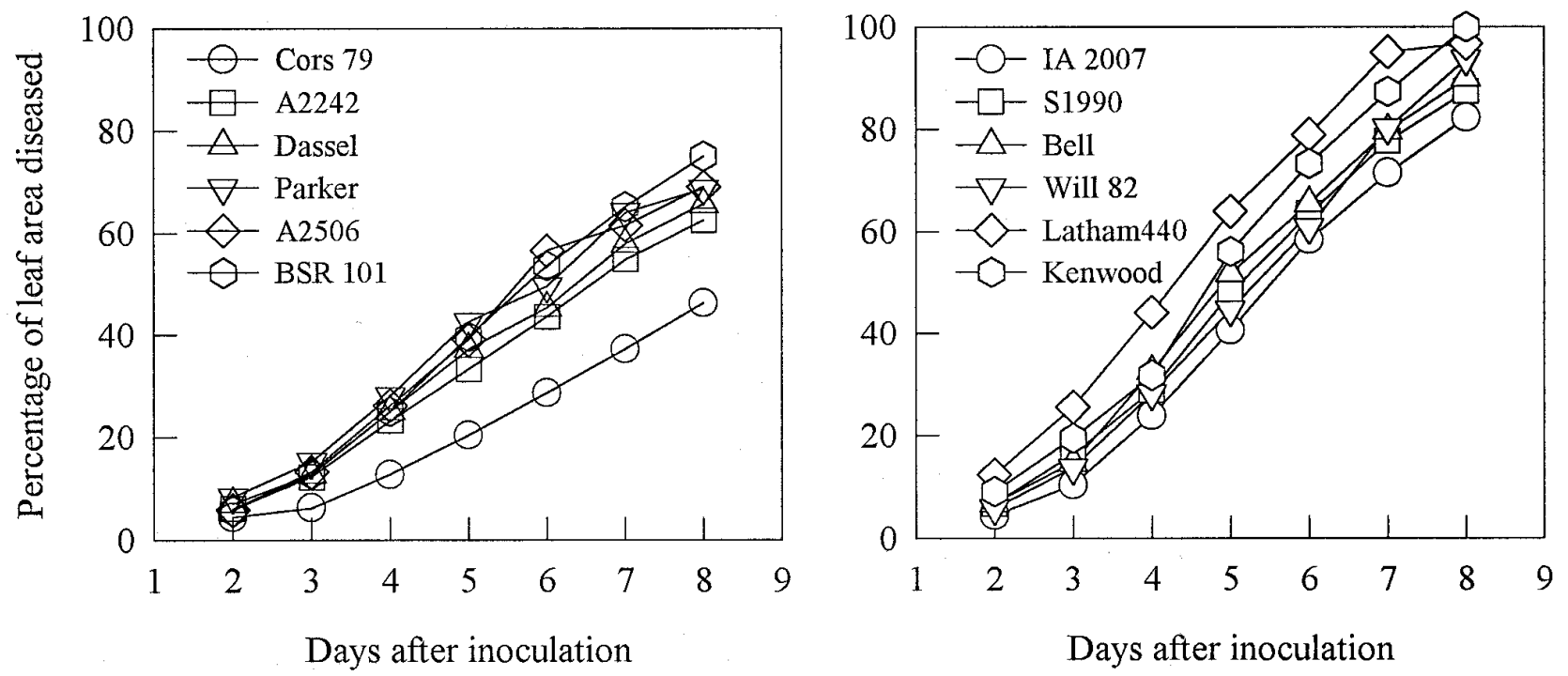

Fig. 1. Lesion development on detached leaves of 12 soybean cultivars inoculated with mycelia of Sclerotinia sclerotiorum and incubated at $20^{\circ} \mathrm{C}$ (experiment 3).

Table 3. Lesion lengths $(\mathrm{cm})$ on stems of 12 soybean cultivars in six experiments inoculated with mycelia of Sclerotinia sclerotiorum on autoclaved carrot disks in the greenhouse, 1997

\begin{tabular}{|c|c|c|c|c|c|c|c|}
\hline \multirow[b]{2}{*}{ Cultivars $^{y}$} & \multicolumn{7}{|c|}{ Lesion length $(\mathrm{cm})$} \\
\hline & 1 & 2 & 3 & 4 & 5 & 6 & Combined \\
\hline Williams 82 & $11.3 \mathrm{a}-\mathrm{c}$ & $7.4 \mathrm{~d}$ & $9.6 \mathrm{a}-\mathrm{d}$ & 7.7 & $9.2 \mathrm{ab}$ & $10.4 \mathrm{a}-\mathrm{c}$ & $9.6 \mathrm{a}-\mathrm{c}$ \\
\hline Kenwood & $15.8 \mathrm{a}$ & $10.1 \mathrm{~b}-\mathrm{d}$ & $8.1 \mathrm{~b}-\mathrm{e}$ & 6.5 & $8.5 \mathrm{a}-\mathrm{d}$ & $9.5 \mathrm{a}-\mathrm{c}$ & $9.9 \mathrm{a}-\mathrm{c}$ \\
\hline Bell & $7.3 \mathrm{~cd}$ & $10.7 \mathrm{~b}-\mathrm{d}$ & $10.9 \mathrm{ab}$ & 9.5 & $7.4 \mathrm{~cd}$ & $9.0 \mathrm{a}-\mathrm{c}$ & $9.1 \mathrm{~cd}$ \\
\hline A2242 & $11.0 \mathrm{a}-\mathrm{c}$ & $12.1 \mathrm{ab}$ & $7.6 \mathrm{~b}-\mathrm{e}$ & 4.6 & $10.0 \mathrm{a}$ & $10.9 \mathrm{ab}$ & $9.3 \mathrm{~b}-\mathrm{d}$ \\
\hline BSR 101 & 9.4 bc & $11.7 \mathrm{a}-\mathrm{c}$ & $9.6 \mathrm{a}-\mathrm{d}$ & 8.1 & $8.1 \mathrm{~b}-\mathrm{d}$ & $10.0 \mathrm{a}-\mathrm{c}$ & $9.5 \mathrm{a}-\mathrm{d}$ \\
\hline Parker & $14.3 \mathrm{a}$ & $10.1 \mathrm{~b}-\mathrm{d}$ & $9.3 \mathrm{a}-\mathrm{e}$ & 8.8 & 8.4 a-d & $11.2 \mathrm{a}$ & $10.4 \mathrm{ab}$ \\
\hline A2506 & $13.9 \mathrm{ab}$ & $8.3 \mathrm{~cd}$ & $11.7 \mathrm{a}$ & 7.6 & $10.0 \mathrm{a}$ & $8.5 \mathrm{~cd}$ & $10.5 \mathrm{ab}$ \\
\hline IA2007 & $7.4 \mathrm{~cd}$ & $7.8 \mathrm{~d}$ & $10.3 \mathrm{a}-\mathrm{c}$ & 7.6 & $8.9 \mathrm{~b}-\mathrm{c}$ & $9.7 \mathrm{a}-\mathrm{c}$ & $8.7 \mathrm{c}-\mathrm{e}$ \\
\hline Latham 440 & $9.4 \mathrm{bc}$ & $10.6 \mathrm{~b}-\mathrm{d}$ & $7.3 \mathrm{c}-\mathrm{e}$ & 4.8 & $7.8 \mathrm{~b}-\mathrm{d}$ & $8.9 \mathrm{bc}$ & $8.3 \mathrm{de}$ \\
\hline Dassel & $12.9 \mathrm{ab}$ & $15.1 \mathrm{a}$ & $8.8 \mathrm{a}-\mathrm{e}$ & 7.4 & $8.7 \mathrm{a}-\mathrm{c}$ & $11.0 \mathrm{ab}$ & $10.6 \mathrm{a}$ \\
\hline S1990 & $6.6 \mathrm{~cd}$ & 10.6 b-d & $6.1 \mathrm{e}$ & 8.5 & $6.9 \mathrm{~d}$ & $6.7 \mathrm{~d}$ & $7.7 \mathrm{ef}$ \\
\hline Corsoy 79 & $3.3 \mathrm{~d}$ & $8.3 \mathrm{~cd}$ & $6.8 \mathrm{de}$ & 3.0 & $8.6 \mathrm{a}-\mathrm{c}$ & $8.4 \mathrm{~cd}$ & $6.5 \mathrm{f}$ \\
\hline $\mathrm{SE}^{\mathrm{z}}$ & 0.5 & 0.3 & 0.3 & 0.4 & 0.2 & 0.2 & 0.1 \\
\hline
\end{tabular}

y Cultivar means followed by the same letter are not significantly different at $P=0.05$ according to Fisher's (protected) least significant difference test.

${ }^{\mathrm{z}}$ Standard error of the mean. 
lesions; whereas Kenwood and Williams 82 had the longest lesions.

Determination of soluble pigment levels in stems. Absorbance values for soluble stem pigment(s) at $518 \mathrm{~nm}$ were highest for IA2007, followed by Dassel and least for Parker, A2242, and Williams 82 in all four replicate experiments (Table 5). On the basis of combined analysis of variance, IA2007, Dassel, Corsoy 79, and S19-90 were the four cultivars with the highest absorbance values. Parker, A2242, Williams 82, and BSR 101 were the four cultivars with the lowest absorbance values (Table 5). Differences in absorbance values were significant $(P \leq 0.05)$ among cultivars in all four experiments (Table 5). Fluctuation in cultivar ranks was least in this method of evaluation; experiment by culti- var interaction was highly nonsignificant $(P=0.9765)$.

Comparison of controlled environment evaluations with field evaluations.

Pearson correlation coefficients $(R)$ between soybean cultivar responses to $S$. sclerotiorum in field experiments and responses to the pathogen in controlled environment experiments varied among and within methods. Values of $R$ varied from 0.01 to 0.62 for detached leaf assays (15 correlation analyses), from -0.20 to 0.47 for mycelial inoculation of stems (18 analyses), from 0.38 to 0.45 for mycelial inoculation of foliage ( 3 analyses), from 0.08 to 0.66 for lesion lengths on stems discolored by oxalic acid (24 analyses), and from -0.55 to -0.37 for levels of soluble stem pigment(s) (12 analyses). Abso- lute values of $R$ were 0.40 or greater in 40 , $17,33,29$, and $83 \%$ of the total number of correlation analyses for detached leaf assays, mycelial inoculation of stems, mycelial inoculation of foliage, lesion lengths on stems discolored by oxalic acid, and levels of soluble stem pigment(s), respectively. Spearman's coefficients of rank correlation $\left(r_{s}\right)$ between controlled environment and field experiments based on average performance were $0.55,-0.20,0.40,0.42$, and -0.44 for detached leaf assays, mycelial inoculation of stems, mycelial inoculation of foliage, lengths of stems discolored by oxalic acid, and levels of soluble stem pigment(s), respectively. There were variations in ranking among field and controlled environment experiments. Corsoy 79, S19-90, and Dassel were consistently
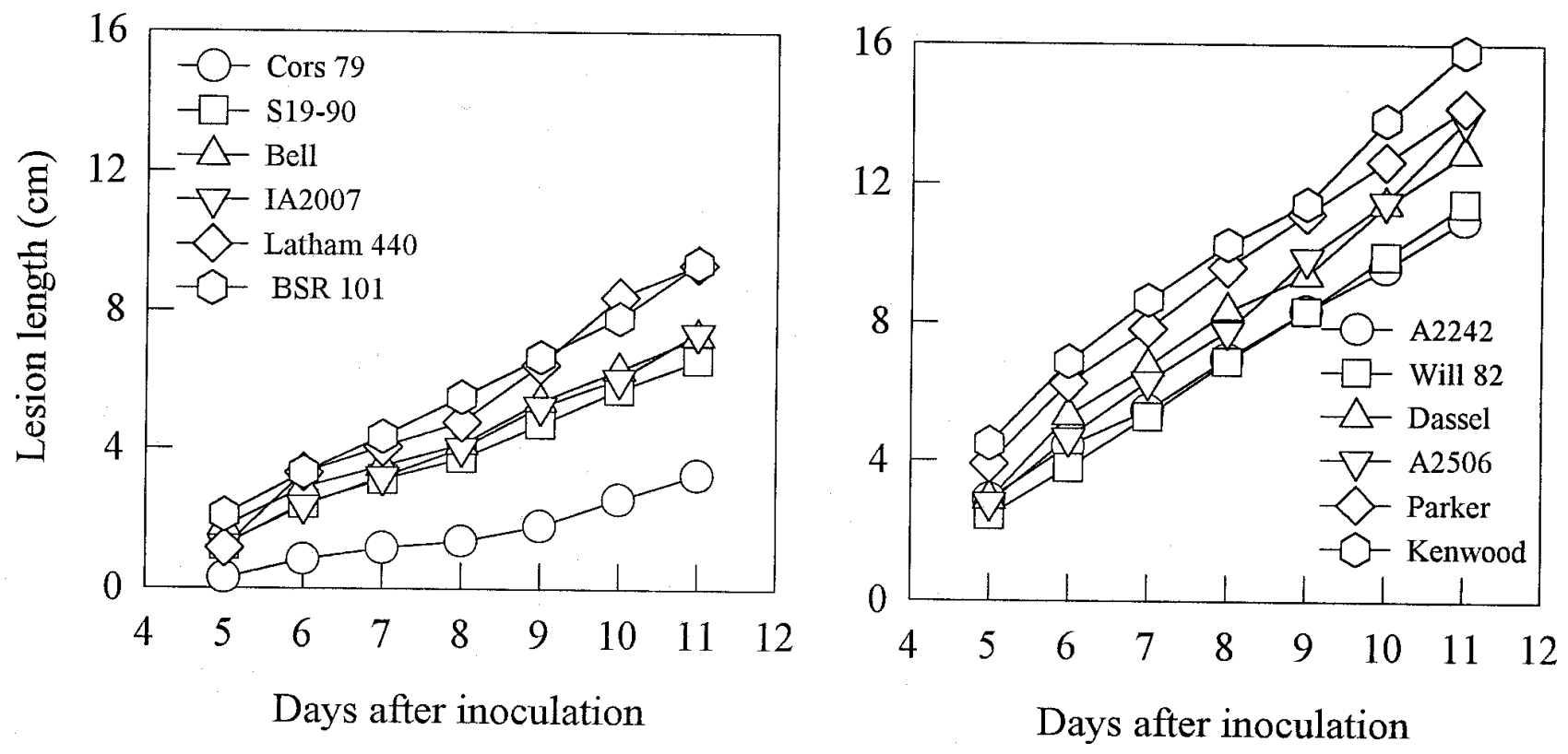

Fig. 2. Lesion development on stems of 12 soybean cultivars inoculated with mycelia of Sclerotinia sclerotiorum and incubated at $18^{\circ} \mathrm{C}$ (experiment 1 ).

Table 4. Lesion lengths $(\mathrm{cm})$ on stems of 12 soybean cultivars severed $0.5 \mathrm{~cm}$ above soil level, defoliated (except the top two fully developed trifoliate leaves), and placed in test tubes containing $10 \mathrm{ml}$ of $40 \mathrm{mM}$ oxalic acid, as a method to evaluate the 12 cultivars in eight experiments ${ }^{\mathrm{x}}$ for field resistance to Sclerotinia sclerotiorum, 1997

\begin{tabular}{|c|c|c|c|c|c|c|c|c|c|}
\hline \multirow[b]{2}{*}{ Cultivars $^{y}$} & \multicolumn{9}{|c|}{ Lesion length (cm) } \\
\hline & 1 & 2 & 3 & 4 & 5 & 6 & 7 & 8 & Combined \\
\hline Williams 82 & $20.5 \mathrm{bc}$ & $26.7 \mathrm{a}$ & $23.1 \mathrm{ab}$ & $22.8 \mathrm{~b}$ & $30.3 \mathrm{a}$ & 33.2 & $21.6 \mathrm{~b}-\mathrm{d}$ & $23.0 \mathrm{ab}$ & $24.9 \mathrm{ab}$ \\
\hline Kenwood & $27.2 \mathrm{a}$ & $25.5 \mathrm{a}$ & $25.7 \mathrm{a}$ & $28.7 \mathrm{a}$ & $23.4 \mathrm{a}-\mathrm{c}$ & 25.1 & $27.6 \mathrm{a}$ & $27.4 \mathrm{a}$ & $26.3 \mathrm{a}$ \\
\hline Bell & $20.8 \mathrm{bc}$ & $24.1 \mathrm{ab}$ & $21.2 \mathrm{a}-\mathrm{c}$ & $21.7 b-d$ & $25.2 \mathrm{ab}$ & 23.2 & $24.0 \mathrm{ab}$ & $23.3 \mathrm{ab}$ & $23.0 \mathrm{bc}$ \\
\hline A2242 & $21.3 \mathrm{bc}$ & $21.4 \mathrm{~b}-\mathrm{d}$ & $20.6 \mathrm{a}-\mathrm{c}$ & $19.0 \mathrm{~b}-\mathrm{e}$ & $29.8 \mathrm{a}$ & 18.8 & $21.0 \mathrm{~b}-\mathrm{d}$ & $20.1 \mathrm{~b}-\mathrm{d}$ & $21.5 \mathrm{c}$ \\
\hline BSR 101 & $20.7 \mathrm{bc}$ & $23.9 \mathrm{ab}$ & $21.3 \mathrm{a}-\mathrm{c}$ & $22.7 \mathrm{bc}$ & $22.2 \mathrm{a}-\mathrm{c}$ & 21.1 & $18.7 \mathrm{~cd}$ & $21.2 \mathrm{~b}-\mathrm{d}$ & $21.5 \mathrm{c}$ \\
\hline Parker & $17.1 \mathrm{~cd}$ & $22.0 \mathrm{bc}$ & $23.1 \mathrm{ab}$ & $20.2 \mathrm{~b}-\mathrm{e}$ & $21.3 \mathrm{bc}$ & 23.6 & $20.3 \mathrm{~b}-\mathrm{d}$ & $22.7 \mathrm{a}-\mathrm{c}$ & $21.3 \mathrm{c}$ \\
\hline A2506 & $24.7 \mathrm{ab}$ & $18.4 \mathrm{~d}-\mathrm{f}$ & $20.6 \mathrm{a}-\mathrm{c}$ & $21.2 \mathrm{~b}-\mathrm{d}$ & $27.2 \mathrm{ab}$ & 19.5 & $22.2 \mathrm{bc}$ & $22.7 \mathrm{a}-\mathrm{c}$ & $22.0 \mathrm{c}$ \\
\hline IA2007 & $19.3 \mathrm{~cd}$ & $19.4 \mathrm{c}-\mathrm{e}$ & $17.8 \mathrm{~cd}$ & $13.7 \mathrm{f}$ & $15.5 \mathrm{c}$ & 17.0 & $16.7 \mathrm{~d}$ & $16.3 \mathrm{~d}$ & $17.0 \mathrm{e}$ \\
\hline Latham 440 & $15.0 \mathrm{~d}$ & $16.4 \mathrm{ef}$ & $19.5 \mathrm{bc}$ & $15.8 \mathrm{ef}$ & $25.6 \mathrm{ab}$ & 18.7 & $18.5 \mathrm{~cd}$ & $19.0 \mathrm{~b}-\mathrm{d}$ & $18.6 \mathrm{de}$ \\
\hline Dassel & $16.8 \mathrm{~cd}$ & $18.8 \mathrm{c}-\mathrm{f}$ & $17.4 \mathrm{~cd}$ & $18.0 \mathrm{c}-\mathrm{f}$ & $19.1 \mathrm{bc}$ & 17.3 & $17.5 \mathrm{~cd}$ & $17.5 \mathrm{~cd}$ & $17.8 \mathrm{de}$ \\
\hline S1990 & $17.0 \mathrm{~cd}$ & $15.6 \mathrm{f}$ & $13.9 \mathrm{~d}$ & $17.3 \mathrm{~d}-\mathrm{f}$ & $21.5 \mathrm{bc}$ & 21.8 & $19.9 \mathrm{~b}-\mathrm{d}$ & $18.7 \mathrm{~b}-\mathrm{d}$ & $18.2 \mathrm{de}$ \\
\hline Corsoy 79 & $18.1 \mathrm{~cd}$ & $19.5 \mathrm{c}-\mathrm{e}$ & $18.1 \mathrm{~b}-\mathrm{d}$ & $17.0 \mathrm{~d}-\mathrm{f}$ & $15.9 \mathrm{c}$ & 21.3 & $19.9 \mathrm{~b}-\mathrm{d}$ & $23.0 \mathrm{ab}$ & $19.1 \mathrm{~d}$ \\
\hline $\mathrm{SE}^{\mathrm{z}}$ & 0.5 & 0.3 & 0.5 & 0.5 & 0.8 & 1.1 & 0.5 & 0.5 & 0.2 \\
\hline
\end{tabular}

${ }^{\mathrm{x}}$ Experiments 1 to 4 were conducted in a greenhouse room where temperature ranged from 22 to $35^{\circ} \mathrm{C}$; experiments 5 to 8 were conducted in a controlled environment chamber at $18^{\circ} \mathrm{C}$.

y Cultivar means followed by the same letter are not significantly different at $P=0.05$ according to Fisher's (protected) least significant difference test.

z Standard error of the mean. 
most resistant, and Williams 82 was consistently least resistant in most experiments (Table 6).

Spearman's coefficients of rank correlation between replicate experiments within each method of evaluation ranged from 0.86 to 0.97 for absorbance at $518 \mathrm{~nm}$ by soluble pigment(s) from stems $(P<0.001$ for $100 \% 6$ correlation analyses), 0.27 to 0.85 for lesion lengths on stems discolored by oxalic acid $\left(r_{s} \geq 0.58\right.$ and significant at $P \leq 0.05$ for $68 \%$ of 28 analyses), -0.46 to 0.57 for lesion lengths on stems inoculated with mycelial disks $(P=0.05$ for $7 \%$ of 15 analyses), and -0.53 to 0.45 for detached leaf assays $\left(r_{s}\right.$ nonsignificant at $\left.P=0.05\right)$. Therefore, the most repeatable methods based on experiment by cultivar interaction and $r_{s}$ values were determination of dissolved pigment levels in stems and measurement of lesion lengths on stems discolored by oxalic acid.

\section{DISCUSSION}

Results from this study indicate that determination of soluble pigment levels in stems and measurement of lesion lengths on stems discolored by oxalic acid may be more reliable methods of evaluating soybean cultivars for resistance to $S$. sclerotiorum than measurement of lesion lengths on stems inoculated with mycelial disks. These two methods were the most repeatable based on Spearman's coefficients of rank correlation between replicate experiments and had better Pearson correlations with field performance than inoculation of stems with mycelial disks. Although the detached leaf assay had better Pearson correlations with field performance compared with inoculation of stems with mycelial disks, this method was the least repeatable. Because of the slow development of stem rot, inoculation of foliage with a mycelial suspension may not be suitable for evaluation of a large number of cultivars for field resistance to $S$. sclerotiorum.

Our results suggest that the soluble pink pigment(s) observed in stems of soybean cultivars may be related to resistance to $S$. sclerotiorum. Levels of this pigment(s) in cultivars were generally inversely related to disease incidence in the field. Although the soluble pigment(s) was not isolated and characterized, the presence of anthocyanins in it is highly likely, on the basis of the similarity in color between the observed pigment(s) and some anthocyanin pigments that have been isolated and characterized $(20,21,23)$. Anthocyanins are a group of pigments widely distributed in plants and are responsible for the pink, red, scarlet, mauve, violet, and blue colors found in plants $(20,21,23)$. They are products of the flavonoid biosynthesis pathway $(9,20-23)$ and have been reported to be involved in disease resistance $(1,2,19,22,25-27)$. The possible involvement of the soluble pigment(s) observed in this study in soybean cultivar resistance to $S$. sclerotiorum requires further investigation.

The findings of this study regarding the existence of differences in responses of soybean cultivars to $S$. sclerotiorum and the consistency of low levels of Sclerotinia stem rot in Corsoy 79 are in agreement with those reported previously $(3,4,6,7$, $15,17,18,29,30)$. A number of studies in which laboratory and field evaluations have been compared have reported varying correlations (6) or no correlation (30). The results of Nelson et al. (30) support the findings from our study that inoculation of stems and subsequent measurement of lesion lengths may not be a reliable method for identifying field resistance to $S$. sclerotiorum. In this study, the time between mycelial inoculation of stems and measurement of lesion lengths was fixed, but the time between inoculation and development of lesions varied widely among and within cultivars. This variation may have contributed, in part, to the low correlation between lesion lengths and incidence of Sclerotinia stem rot in the field.

Despite the low level of repeatability reported in this study for the detached leaf assay, the method appears to be useful in evaluating soybean cultivars for resistance to $S$. sclerotiorum. To ensure the consistency of this assay, three factors that should be considered are uniformity of leaf size, placement of inoculum on the leaf blade, and adequate moisture in the environment surrounding the inoculated leaves. Variations among replicate experiments were partly attributable to the use of different sizes of leaves among experiments and cultivars within the same experiment. Computer-aided measurement of diseased leaf area may be more accurate and precise than the method used in this study. Because the rate of lesion development on detached leaves was linear, it was sufficient to use

Table 5. Absorbance values $(518 \mathrm{~nm}$ ) of soluble pigment(s) dissolved in $5 \mathrm{ml}$ of $40 \mathrm{mM}$ oxalic acid from defoliated stems (V1 or V2 growth stage; 1 stem per test tube) of 12 greenhouse-grown soybean cultivars; one of the methods used to evaluate soybean cultivars for field resistance to Sclerotinia sclerotiorum, 1997

\begin{tabular}{llllll}
\hline & \multicolumn{5}{c}{ Absorbance (518 nm) } \\
\cline { 2 - 6 } Cultivars $^{\mathbf{y}}$ & $\mathbf{1}$ & $\mathbf{2}$ & $\mathbf{3}$ & $\mathbf{4}$ & Combined \\
\hline IA2007 & $0.040 \mathrm{a}$ & $0.047 \mathrm{a}$ & $0.038 \mathrm{a}$ & $0.032 \mathrm{a}$ & $0.039 \mathrm{a}$ \\
Dassel & $0.029 \mathrm{ab}$ & $0.036 \mathrm{ab}$ & $0.031 \mathrm{a}$ & $0.022 \mathrm{ab}$ & $0.029 \mathrm{~b}$ \\
A2506 & $0.019 \mathrm{bc}$ & $0.014 \mathrm{c}-\mathrm{f}$ & $0.017 \mathrm{bc}$ & $0.019 \mathrm{a}-\mathrm{c}$ & $0.017 \mathrm{~cd}$ \\
Corsoy 79 & $0.018 \mathrm{bc}$ & $0.025 \mathrm{c}-\mathrm{d}$ & $0.028 \mathrm{ab}$ & $0.015 \mathrm{a}-\mathrm{d}$ & $0.021 \mathrm{c}$ \\
Latham 440 & $0.015 \mathrm{~b}-\mathrm{d}$ & $0.008 \mathrm{ef}$ & $0.013 \mathrm{~cd}$ & $0.014 \mathrm{~b}-\mathrm{d}$ & $0.013 \mathrm{de}$ \\
S1990 & $0.015 \mathrm{~b}-\mathrm{d}$ & $0.026 \mathrm{bc}$ & $0.027 \mathrm{ab}$ & $0.016 \mathrm{a}-\mathrm{d}$ & $0.021 \mathrm{c}$ \\
Kenwood & $0.014 \mathrm{~cd}$ & $0.011 \mathrm{c}-\mathrm{f}$ & $0.012 \mathrm{~cd}$ & $0.015 \mathrm{a}-\mathrm{d}$ & $0.013 \mathrm{de}$ \\
Bell & $0.014 \mathrm{~cd}$ & $0.022 \mathrm{c}-\mathrm{f}$ & $0.016 \mathrm{bc}$ & $0.021 \mathrm{ab}$ & $0.018 \mathrm{~cd}$ \\
BSR 101 & $0.008 \mathrm{~cd}$ & $0.009 \mathrm{~d}-\mathrm{f}$ & $0.009 \mathrm{~cd}$ & $0.005 \mathrm{~b}-\mathrm{d}$ & $0.008 \mathrm{ef}$ \\
Williams 82 & $0.002 \mathrm{~d}$ & $0.005 \mathrm{f}$ & $0.003 \mathrm{~d}$ & $0.001 \mathrm{~cd}$ & $0.003 \mathrm{f}$ \\
A2242 & $0.001 \mathrm{~d}$ & $0.003 \mathrm{f}$ & $0.002 \mathrm{~d}$ & $0.000 \mathrm{~d}$ & $0.002 \mathrm{f}$ \\
Parker & $0.002 \mathrm{~d}$ & $0.001 \mathrm{f}$ & $0.001 \mathrm{~d}$ & $0.000 \mathrm{~d}$ & $0.001 \mathrm{f}$ \\
SE & 0.001 & 0.002 & 0.001 & 0.002 & 0.001 \\
\hline
\end{tabular}

y Cultivar means followed by the same letter are not significantly different at $P=0.05$ according to Fisher's (protected) least significant difference test.

${ }^{\mathrm{z}}$ Standard error of the mean.

Table 6. Ranks of 12 soybean cultivars $(1=$ most resistant, $12=$ least resistant $)$ by six methods ${ }^{y}$ of evaluation for resistance to Sclerotinia sclerotiorum, 1995 to 1997

\begin{tabular}{lcrrrrr}
\hline & \multicolumn{7}{c}{ Rank } \\
\cline { 2 - 7 } Cultivar & $\mathbf{1 ( 3 )})^{\mathbf{z}}$ & $\mathbf{2 ( 5 )}$ & $\mathbf{3 ( 6 )}$ & $\mathbf{4 ( 1 )}$ & $\mathbf{5 ( 8 )}$ & $\mathbf{6 ( 4 )}$ \\
\hline Corsoy 79 & 3 & 2 & 1 & 1 & 5 & 3 \\
S19-90 & 4 & 3 & 2 & 2 & 3 & 4 \\
Dassel & 1 & 6 & 12 & 3 & 2 & 2 \\
IA2007 & 9 & 10 & 4 & 5 & 1 & 1 \\
Parker & 5 & 1 & 11 & 9 & 6 & 12 \\
Latham 440 & 6 & 9 & 3 & 8 & 4 & 8 \\
A2506 & 2 & 4 & 10 & 11 & 9 & 6 \\
BSR101 & 8 & 5 & 8 & 6 & 7 & 9 \\
Bell & 10 & 7 & 5 & 12 & 10 & 5 \\
Kenwood & 7 & 11 & 9 & 4 & 12 & 7 \\
A2242 & 12 & 8 & 7 & 7 & 8 & 11 \\
Williams 82 & 11 & 12 & 6 & 10 & 11 & 10 \\
\hline
\end{tabular}

y Method 1, average performance determined from disease incidence in field trials; method 2, percentage of leaf area diseased in detached leaf assays; method 3, lesion lengths on stems inoculated with mycelial disks; method 4 , incidence of stem rot from inoculation of foliage with a mycelial suspension; method 5, lesion lengths on stems placed in $40 \mathrm{mM}$ oxalic acid; and method 6, absorbance at $518 \mathrm{~nm}$ by soluble stem pigment(s) from seedling stems.

${ }^{\mathrm{z}}$ Numbers in parentheses are numbers of replicate experiments within each method. 
only final percentage of leaf area covered with lesions rather than the rate of lesion development for comparison among cultivars. Use of data from one assessment date can be economical and time-saving when the number of cultivars under evaluation is large.

Based on observations in this study, measurement of soybean stem discoloration by oxalic acid may work better with seedlings at the V1 or V2 growth stage, in which experimental error resulting from the effect of woody tissue on diffusion of oxalic acid in stems may be reduced. In other studies, Tu (36) distinguished between $S$. sclerotiorum-tolerant and -susceptible bean (P. vulgaris) by the rate of diffusion of ${ }^{14} \mathrm{C}$ oxalic acid in leaves, and Noyes and Hancock (31) developed a sunflower (H. annuus) screening test based on resistance of sunflower leaf cells to lysis by oxalic acid.

The reasons for fluctuations in cultivar ranking among different methods of evaluating soybean germ plasm for resistance to $S$. sclerotiorum in field and controlled environment studies may be due, in part, to differences in the defense repertoire among cultivars. Some cultivars may vary their defense strategies depending on environmental conditions or the method of resistance evaluation employed. In this study, the cultivar Parker, which was rated susceptible when resistance evaluation was based on levels of dissolved stem pigments, was found in a separate study (37) to have high levels of constitutive isoflavone glucosyl conjugates (which are known to play an important role in the general defense response in soybean) and to have the ability to synthesize large amounts of these compounds following inoculation with $S$. sclerotiorum. In contrast, the susceptible Williams 82 had low levels of isoflavone glucosyl conjugates both prior to and following inoculation with $S$. sclerotiorum.

Several methods that may be useful in evaluating soybean cultivars for resistance to $S$. sclerotiorum, or that may provide a basis for developing more reliable methods, have been presented. We used only one isolate because of the extensive nature of our study. Isolates of the pathogen that differ widely in virulence from the isolate we used may respond differently in resistance evaluations of soybean cultivars using our protocols. More research is required to determine the consistency and nature of the observations made in this study among a greater number of cultivars and segregating germ plasm.

\section{ACKNOWLEDGMENTS}

We thank Tom Gulya, North Dakota State University, for providing sclerotia used as inoculum in field studies. We also thank Peter Lundeen and Dave Volkers for their assistance in the field and in the greenhouse. We are indebted to Thomas Baum, Soum Sanogo, and Mike Uphoff for reviewing the manuscript, and to Gary Munkvold for suggestions on data analysis.

\section{LITERATURE CITED}

1. Biehn, W. L., Kuc, J., and Williams, E. B. 1968. Accumulation of phenols in resistant plant-fungi interactions. Phytopathology 58:1255-1260.

2. Biehn, W. L., Williams, E. B., and Kuc, J. 1968. Fungitoxicity of phenols accumulating in Glycine max-fungi interactions. Phytopathology 58:1261-1264.

3. Boland, G. J., and Hall, R. 1986. Growth room evaluation of soybean cultivars for resistance to Sclerotinia sclerotiorum. Can. J. Plant Sci. 66:559-564.

4. Boland, G. J., and Hall, R. 1987. Evaluating soybean cultivars for resistance to Sclerotinia sclerotiorum under field conditions. Plant Dis. 71:934-936.

5. Buzzel, R. I., Welacky, T. W., and Anderson, T. R. 1993. Soybean cultivar reaction and row width effect on Sclerotinia stem rot. Can. J. Plant Sci. 73:1169-1175.

6. Chun, D., Kao, L. B., and Lockwood, J. L. 1987. Laboratory and field assessment of resistance in soybean to stem rot caused by Sclerotinia sclerotiorum. Plant Dis. 71:811815.

7. Cline, M. N., and Jacobsen, B. J. 1983. Methods for evaluating soybean cultivars for resistance to Sclerotinia sclerotiorum. Plant Dis. 67:784-786.

8. Coley-Smith, J. R., and Cooke, R. C. 1971. Survival and germination of fungal sclerotia. Annu. Rev. Phytopathol. 9:65-92.

9. Deikman, J., and Hammer, P. E. 1995. Induction of anthocyanin accumulation by cytokinins in Arabidopsis thaliana. Plant Physiol. 108:47-57.

10. Dillard, H. R., Ludwig, J. W., and Hunter, J. E. 1995. Conditioning sclerotia of Sclerotinia sclerotiorum for carpogenic germination. Plant Dis. 79:411-415.

11. Doupnik, B., Jr. 1993. Soybean production and disease loss estimates for north central United States from 1989 to 1991. Plant Dis. 77:1170-1171

12. Fehr, W. R., Caviness, C. E., Burmood, D. T., and Pennington, J. S. 1971. Stage of development descriptions for soybeans, Glycine $\max ($ L.) Merrill. Crop Sci. 11:929-931.

13. Ferrar, P. H., and Walker, J. R. L. 1993. oDiphenol oxidase inhibition-an additional role for oxalic acid in the phytopathogenic arsenal of Sclerotinia sclerotiorum and Sclerotium rolfsii. Physiol. Mol. Plant Pathol. 43:415422.

14. Godoy, G., Steadman, J. R., Dickman, M. B., and Dam, R. 1990. Use of mutants to demonstrate the role of oxalic acid in pathogenicity of Sclerotinia sclerotiorum on Phaseolus vulgaris. Physiol. Mol. Plant Pathol. 37:179-191.

15. Grau, C. R., and Bissonette, H. L. 1974. Whetzelinia stem rot on soybeans in Minnesota. Plant Dis. Rep. 58:693-695.

16. Grau, C. R., and Oplinger, E. S. 1996. White mold of soybean in the Midwest. Pages 153157 in: Annu. Midwest Soybean Conf., 1st. Iowa Soybean Association.

17. Grau, C. R., and Radke, V. L. 1984. Effects of cultivars and cultural practices on Sclerotinia stem rot of soybean. Plant Dis. 68:56-58.

18. Grau, C. R., Radke, V. L., and Gillespie, F. L. 1982. Resistance of soybean cultivars to Sclerotinia sclerotiorum. Plant Dis. 66:506-508.

19. Hammerschmidt, R., and Nicholson, R. L. 1977. Resistance of maize to anthracnose:
Changes in host phenols and pigments. Phytopathology 67:251-258.

20. Harborne, J. B. 1965. Flavonoid pigments. Pages 618-640 in: Plant Biochemistry. J. Boner and J. E. Varner, eds. Academic Press, New York.

21. Harborne, J. B. 1967. Comparative Biochemistry of the Flavonoids. Academic Press, London.

22. Harborne, J. B. 1976. Functions of flavonoids in plants. Pages 736-778 in: Chemistry and Biochemistry of Plant Pigments. T. W. Goodwin, ed. Academic Press, London.

23. Hrazdina, G. 1982. Anthocyanins. Pages $135-$ 188 in: The Flavonoids. Advances in Research. J. B. Harborne and T. J. Mabry, eds. Chapman and Hall, London.

24. Hunter, J. E., Dickson, M. H., and Cigna, J. A. 1981. Limited-term inoculation: A method to screen bean plants for partial resistance to white mold. Plant Dis. 65:414-417.

25. Kraft, J. M. 1977. The role of delphinidin and sugars in the resistance of pea seedlings to Fusarium root rot. Phytopathology 67:10571061.

26. Kumar, J., Kaiser, W. J., and Hannan, R. M. 1991. Damping-off resistance in chickpeas. Plant Dis. 75:1244-1245.

27. Muehlbauer, F. J., and Kraft, J. M. 1978. Effect of pea seed genotype on pre-emergence damping off and resistance to Fusarium and Pythium root rot. Crop Sci. 321-323.

28. Nelson, B., Duval, D., and Wu, H. 1988. An in vitro technique for large-scale production of sclerotia of Sclerotinia sclerotiorum. Phytopathology 78:1470-1472.

29. Nelson, B. D., Helms, T. C., and Kural, I. 1991. Effects of temperature and pathogen isolate on laboratory screening of soybean for resistance to Sclerotinia sclerotiorum. Can. J. Plant Sci. 71:347-352.

30. Nelson, B. D., Helms, T. C., and Olson, M. A. 1991. Comparison of laboratory and field evaluations of resistance to Sclerotinia sclerotiorum. Can. J. Plant Sci. 71:347-352.

31. Noyes, R. D., and Hancock, J. G. 1981. Role of oxalic acid in the Sclerotinia wilt of sunflower. Physiol. Plant Pathol. 18:123-132.

32. Pennypacker, B. W., and Hatley, O. E. 1995. Greenhouse technique for detection of physiological resistance to Sclerotinia sclerotiorum in soybean. (Abstr.) Phytopathology 85:1178.

33. Pratt, R. G., and Rowe, D. E. 1998. Evaluation of simplified leaf inoculation procedures for identification of quantitative resistance to Sclerotinia trifoliorum in alfalfa seedlings. Plant Dis. 82:1161-1164.

34. Steel, R. G. D., Torrie, J. H., and Dickey, D. A. 1997. Principles and Procedures of Statistics: A Biometrical Approach. McGraw-Hill, New York.

35. Tories, J. A., and Moreno, R. 1987. Lesion development factors following inoculation of Sclerotinia sclerotiorum mycelium to eggplant, tomato, and french bean. Phytoparasitica 15:325-333.

36. Tu, J. C. 1989. Modes of primary infection caused by Sclerotinia sclerotiorum in navy bean. Microbios 57:85-91.

37. Wegulo, S. N. 1997. Soybean cultivar responses to and epidemiological studies of Sclerotinia sclerotiorum. Ph.D. diss. Iowa State University, Ames.

38. Wrather, J. A., Anderson, T. R., Arsyad, D. M., Gai, J., Ploper, L. D., Porta-Puglia, A., Ram, H. H., and Yorinori, J. T. 1997. Soybean disease loss estimates for the top 10 soybean producing countries in 1994. Plant Dis. 81:107-110. 